\title{
A REVIEW: BIOLOGICAL ACTIVITY OF MYRTENAL AND SOME MYRTENAL-CONTAINING MEDICINAL PLANT ESSENTIAL OILS
}

\author{
Stela Dragomanova ${ }^{1,2}$, Lyubka Tancheva ${ }^{2}$, Marieta Georgieva ${ }^{1}$ \\ ${ }^{1}$ Department of Pharmacology, Toxicology and Pharmacotherapy, Faculty of Pharmacy, \\ Medical University of Varna, Bulgaria \\ ${ }^{2}$ Institute of Neurobiology, Bulgarian Academy of Sciences
}

\begin{abstract}
INTRODUCTION: Myrtenal, a component of many plants' essential oils, is a bicyclic monoterpenoid. Numerous effects of myrtenal in experimental animals have been found - bronchodilatory, anti-inflammatory, anti-aggregative and antihemolytic (in vitro), and antibacterial. Its other activities have been studied antioxidant, antitumor, antihyperglycemic, vasodilating, heart rate reducing and hypotensive. Myrtenal is relatively little studied in the field of neuroscience.

AIM: The aim of this article is to summarize the available information on the established biological activity of the monoterpenoid myrtenal.

MATERIALS AND METHODS: Scientific databases such as PubMed, ResearchGate, HMDB and others have been used to provide information on the published results of properties and activities of the test substance (myrtenal) over a period of 15 years $(2003-2018)$.

RESULTS: Our research confirmed the available data for its central nervous system (CNS) activity - anxiolytic and potentiating the effects of the hypnotic drugs, as well as the antioxidant properties. We have evaluated the neuromodulatory activity of $M$ in brain tissue manifested in elevated levels of major neurotransmitters in healthy rodents and those with neurodegenerative changes accompanied by improvement in the animals' memory.

CONCLUSION: Significant protective effects of myrtenal on neurodegenerative processes were established. Probably they are related to its complex mechanisms, including neuromodulatory and antioxidant properties.
\end{abstract}

Keywords: myrtenal, biological activity, neurodegeneration

Address for correspondence:

Stela Dragomanova

Faculty of Pharmacy

Medical University of Varna

84 Tzar Osvobodite Blvd

9000 Varna

e-mail: stela.dragomanova@mu-varna.bg

Received: November 14, 2018

Accepted: December 22, 2018

\section{INTRODUCTION}

The study of biologically active substances as promising agents for the therapy and prevention of multiple diseases is an important trend in modern experimental science.

Terpenoids are a huge group of substances isolated from plant volatile oils. A natural product called terpene was found in the pine resin in 1818. The Ger- 
Stela Dragomanova, Lyubka Tancheva, Marieta Georgieva

man chemist Otto Wallach defined the structure of the terpenes in 1877 . They are produced by many bacteria, fungi, plants and animals and have an important biological role.

Many of the essential oils have been used in folk medicine as cures, as well as perfumes and fragrances long before their study began. Some of their components have biological activity and are used as medicines. Such substances are the taxanes (with antitumor activity), artemisin (with antimalarial activity), etc. The study of this large group of substances with a complex mechanism of action, many of which show anti-inflammatory, antibacterial or antiviral activity, as potential pharmaceutical agents continues in various fields of medicine (1). Some terpenes have shown potential effects in Alzheimer's disease (2) - ginsenosides, ginkgolides, and cannabinoids have shown promising results in in vitro and in vivo studies. Oleanolic acid, ursolic acid and many others are also studied. The mechanisms of action are different - affecting acetylcholinesterase activity, reducing $A \beta$-aggregation, reducing oxidative stress in various ways, etc.

Monoterpenes, as components of essential oils, are plants' secondary metabolites. They have various pharmacological properties, including antifungal, antibacterial, antioxidant, anticancer, spasmolytic, hypotensive and vasodilating activity. The general mechanism of action of monoterpenes, such as their antimicrobial and antitussive activity, is mainly related to their volatility. They have good distribution, pass through membrane barriers and interact with different biomolecules, assuming their action is non-specific and lacking activity against certain receptors in the body. Non-specific and noncompetitive mechanism of action in the muscle-relaxing effect of some monoterpenes has been established (carvacrol) (3). Their hydrophobicity, as well as the essential oils as a whole, determine their effect on bacterial cell structures (e.g., cell membrane) with a subsequent antimicrobial effect (4).

Biological Effects and Specific Mechanisms of Action of Monoterpenes

Specific effects of monoterpenes on receptors have also been reported, such as the cooling effect of menthol by modulating the thermoreceptors. Although its effects as a nasal decongestant have no specific mechanism, its other mechanisms of action continue to be the subject of discussion (5). Noncompetitive receptor inhibition is characteristic of the interaction of linalool with $\mathrm{N}$-methyl-D-aspartate (NMDA) receptors (6) as well as that of borneol with $\mathrm{N}$-cholinergic receptors (7).

In vitro and in vivo studies have revealed the effects of monoterpenes in diabetes, insulin resistance and obesity (8). In vitro studies on various cell lines (including pancreatic $\beta$ cells, muscle, adipocyte and hepatic cells) revealed that besides carvacrol and thymol that have a phenolic skeleton, most monoterpenes do not have the properties of direct radical scavengers due to their antidiabetic effects. Many natural flavonoids and polyphenols inhibit $\alpha$-amylase and $\alpha$-glucosidase at low (micromolar) concentrations but are of no therapeutic significance $(9,10)$. Various experiments confirm that monoterpenes effectively increase glucose utilization by influencing a glucose transporter (GLUT4) with the participation of some key pharmacological targets at the molecular level, including the insulin signaling pathway. Genipin and geniposide, as well as the iridoids and their glycosides exhibit antidiabetic properties in vitro. Geniposide stimulates insulin secretion by activating the glucagon-like-1 receptor (11). Monoterpenes show promising antidiabetic effect in vivo (12) - elevation of liver glycogen levels (one of the main targets for antidiabetic drugs) was observed for borneol, citronellol and myrtenal. Carvacrol, carvone, citronellol, geniposide, myrtenal и paeoniflorin modulate key liver enzymes of glucose metabolism and decrease the activity of glucokinase and glucose-6-phosphate dehydrogenase.

The role of inflammation as a link between diabetes and obesity has been established (13). Many monoterpenes exhibit ameliorative effects in inflammatory conditions associated with diabetes. By influencing key enzymes for the synthesis of fatty acids (acetyl-CoA carboxylase and synthase) in in vitro studies the direct improving effect of monoterpenes on lipid profile has been reported (14).

The analgesic effect of many plant essential oils rich in monoterpenes has been established experimentally (15).

Positive effects as radiotherapy supplementation of cancer diseases are observed in some mono- 
terpenes. They act as "radiosensitizers" - increase in vitro the sensitivity of cancer cells (head and neck tumors) to radiation therapy with subsequent induction of apoptosis (16).

Memory-enhancing effects for some of the investigated monoterpenes - thymol (17) and carvacrol (18), by influencing different mechanisms have also been reported. Some of the bicyclic monoterpenoids suppress the acetylcholinesterase activity, which is increased in patients with Alzheimer's disease. In a study of 17 representatives of these substances, $(+)$ and (-) - $\alpha$-pinene and (+) - 3-carne appeared as potent inhibitors of the enzyme, while the bicyclic ketones and alcohols were weak (19).

\section{AIM}

The aim of this work is to summarize the available information on the established biological activity of the monoterpenoid Myrtenal in the literature.

Myrtenal ((-)-Myrtenal, (1R)-2-Pinen-10-al, (1R)-6,6-Dimethylbicyclo[3.1.1] hept-2-en-2-carboxaldehyde) is a bicyclic monoterpenoid (Fig. 1).

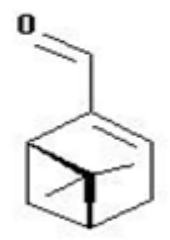

\section{Fig. 1. Chemical structure of myrtenal}

\section{MATERIALS AND METHODS}

Scientific databases such as PubMed, ResearchGate, HMDB and others have been used to provide information on the published results of properties and activities of the test substance (myrtenal) over a period of the past 15 years $(2003-2018)$.

\section{Sources of Myrtenal in Nature}

It is found in plant species, many of which are typical of Bulgaria - Cuminum cyminum - 28-43.5 $=\%$ in some varieties (20); Rosmarinus officinalis $5 \%$ (21); Coriandrum sativum (22); Hyssopus officinalis $-2.32=\%$ (23); Lavandula spp. $-0.1=\%$ (24); Artemisia spp. - myrtenal combination with myrtenol was found to be at the highest concentrations in $A$. pontica, $L$, A. vulgaris, $L$ и A. alba, $L$ (25); Curcuma amada, Curcuma aromatica (26); Origanum majora- na, Origanum vulgare (27); Helianthus annuus (28); Juglans regia (29); Glycirrhyza glabra; Laurus nobilis; Piper nigrum; Peumus boldus (30); Thymus spp. (31); Myrtus communis (32) and many more. Myrtenal is also found in essential oils of orange, lemon, peppermint, juniper, ginger, parsley and others (33), as well as in propolis (34).

Myrtenal-Containing Medicinal Plants and the Biological Activities of their Volatile Oils

Cumminum cyminum exhibits numerous effects - antimicrobial, insecticidal, anti-inflammatory, analgesic (35), antioxidant, anti-tumor, antidiabetic, anti-aggregative, hypotensive, bronchodilator, contraceptive, etc. It affects positively osteoporotic changes, amyloidogenesis, suppresses the activity of a number of enzymes and is an organoprotector (nephro-, hepato- and gastro-protector) (36). It is widely used as a spice in folk medicine. Fruits contain 2.5 - 4.5\% essential oil with established anti-inflammatory activity (37) as its main components vary according to the geographic region. One of the major components of the essential oil in the Tunisian variety with antimicrobial, antimycotic and antioxidant activity is myrtenal (3.5\%) (38). This component, isolated from the plant in the region of Bulgaria, with no traces of myrtenal, exhibits mainly antibacterial effect (39). The plant's essential oil administered to mice causes a significant dose-dependent decrease in lipid peroxidation and elevated levels of reduced glutathione, which is a prerequisite for the study of its effects on carcinogenesis (40). It also exhibits anti-epileptic properties by influencing the transmission of action potential in the central nervous system (CNS) (41). Positive effects on induced stress and memory stimulation of healthy and dementia rats were observed in combination with decreased levels of lipid peroxidation (42). Cumin extract improves the lipid profile in rats (43) and humans (44). There was a significant decrease in oxLDL (oxidated low-density lipoproteins) levels in patients with hypercholesterolemia and an increase in paraoxonase 1 activity (with a protective role in the oxidation of plasma lipoproteins and important for atherosclerotic lesions) (45). The effects of Cumin cyminum in patients with diabetes associated with altered leptin levels, paraoxonase 1, glycated hemoglobin, and lipid profile are better than vitamin $\mathrm{E}$. 
Apart from ethnopharmacological data, the therapeutic potential of Rosmarinus officinalis, $\boldsymbol{L}$. has long been known. Studies of plant extract and the essential oil show antibacterial (46), choleretic, diuretic, hepatoprotective (47), anti-inflammatory and analgesic $(48 ; 49)$, antioxidant $(50)$, anticolytic (51), antiulcerogenic (52) and anti-tumor (53) effects. A study of the analgesic effects of rosemary essential oil found that higher concentrations had better effects according to the Hot plate test and that combining it with codeine or paracetamol potentiated the analgesic effects (54). Rosemary essential oil, aqueous extract and raw plant powder enhance the activity of superoxide dismutase and total antioxidant capacity, reduce the deleterious effect of lipid peroxidation in vivo on hyperlipidemic rats. The plant has a significant inhibitory effect on elevated serum levels of total cholesterol and triglycerides, and antagonizes the elevated levels of lipid peroxidation induced by a high fat diet in vivo (55). The total plant extract also regulates glucose and lipid metabolism in in $v i$ tro studies (56). The intraperitoneal injection of rosemary essential oil in mice results in a significant increase in spontaneous motor activity which is indicative of CNS stimulation (57). The antidepressant effects of Rosmarinus off. in acute and repetitive administration are comparable to fluoxetine and have been shown to be associated with a response to serotonergic, noradrenergic and dopaminergic systems (58). In a study of the effects on long-term and short-term memory in the oral administration of a water-alcoholic extract of rosemary in mice, higher doses demonstrated a positive influence on longterm memory (59). In humans, essential oil (inhaled) produces a significant improvement in performance and overall memory quality but worsens the memory speed compared to controls (60). According to a recent study, rosemary essential oil components exhibit antioxidant neuroprotection, positively influencing neuroinflammation and the formation of amyloid deposits with possible benefits in Alzheimer's disease (AD) (61). The plant extract exhibits neuroprotective properties and affects neurodegenerative damage caused by oxidative stress and apoptosis effectively reducing mitochondrial membrane damage and suppressing apoptosis induced by elevated levels of hydrogen peroxide. It also successfully decreases caspase activity (3 and 9) (62). It also stimu- lates neuronal growth and and increases the levels of Ach (acetylcholine) similar to neuronal growth factor (NGF) in vitro with its potential use in neurodegenerative diseases (63).

The essential oil of Lavandulla spp. has many biological effects - antibacterial, antifungal, carminative (smooth muscle relaxing), sedative and effective for burns and insect bites. However, its possible therapeutic benefits are contradictory (64). The anxiolytic and antidepressant effects of the essential oil in inhalation (65), as well as the injection of total plant extract (66) in combination with improved memory functions in experimental rodents with induced dementia, have recently been established.

Similar CNS effects are also observed with the use of $\alpha$-pinene (67) as one of the main and most widely represented components of plant essential oils.

The biological properties of essential oils of Myrtaceae species have long been studied and are still being investigated (68).

Research on the active components of Myrtus communis L. and their pharmacological properties reveals a wide range of effects - antioxidant, anticancer, antidiabetic, antiviral, antibacterial, antimycotic, hepatoprotective and neuroprotective (69). Extracts from different parts of the plant moderately inhibit the activity of acetylcholinesterase, butyrylcholinesterase and exhibit antioxidant effects in vitro (70) with the potential to influence neurodegeneration. According to other studies, the plant extract demonstrated in vitro both potent cholinesterase and burylesterase inhibiting properties, and it also inhibited lipoxygenase (71). The main compounds of myrtle essential oil are monoterpenoids, flavonoids and triterpenoids. Antimicrobial (72), antioxidant (73), anti-rheumatic and anti-inflammatory $(68,74)$ effects of myrtle essential oil have been established. The anxiolytic properties of Myrtus communis essential oil (75) are compared with those of diazepam. Better effects of the volatile oil have been identified than the reference, with possible mechanisms influencing GABA-ergic neurotransmission. Anxiolytic effects have also been reported after treatment with the entire complex of biologically active substances of the plant (76). Myrtus communis essential oil also prolongs barbiturate-induced sleep in mice (77). 
Biological Effects of Bicyclic Monoterpenoid Myrtenal (Alone)

The observed effects typical of medicinal plants and their essential oils that were reported for the bicyclic monoterpenoid, as well as the biological properties of $\alpha$-pinene whose secondary metabolite is myrtenal, suggest that it is a potential carrier of some of the observed biological activities.

Myrtenal, as a lipid molecule, is considered practically insoluble in water and relatively neutral. In the cell, it is mainly located in the membrane (predicted according to the $\log \mathrm{P}$ value) and the cytoplasm. It has a membrane-stabilizing action supporting the building and maintenance of structurally sound and functioning cell or organelle membranes (78) .

Its metabolism data in mammals are limited $(79 ; 80)$ and its toxicological characteristics are incomplete (81). In plants, myrtenal is metabolically bound to a-pinene (82). In a bio-catalytic process, a-pinene is transformed into myrtenol with subsequent conversion to myrtenal (83).

In the 20th century, numerous effects of myrtenal in experimental animals were found - bronchodilatory, anti-inflammatory, anti-aggregative and antihemolytic (in vitro), and antibacterial (vs. G (+) pathogens) (84). This explains the use of plant essential oils containing myrtenal in aromatherapy in upper respiratory tract infections and in cardiovascular diseases (85) due to induced vasodilatation, heart rate reduction and hypotension in experimental conditions (86).

Antioxidant and antitumor activity of myrtenal has also been reported in various mechanisms - influencing apoptotic and pro-apoptotic signaling pathways, stabilizing intrinsic antioxidant protection, suppressing TNF- $\alpha$ (88) expression and activating suppression of tumor growth, regulating the activity of a number of lysosomal and mitochondrial enzymes, influencing the processes of gluconeogenesis in tumor cells $(71,87,89,90)$. The results obtained in our studies confirm the presence of antioxidant effects of myrtenal in the brain of intact laboratory rats (91), as well as in chemically induced dementia rat models (92). Oxidative status in intact laboratory rats' brain demonstrated decreased SOD (superoxide dismutase) activity, decreased MDA (malon di- aldehyde) levels and increased tGSH (total glutathione) content in the myrtenal group compared to controls. Myrtenal caused memory improvement in the behavioral tests and had a preventive effect on oxidative damages in the brain induced by scopolamine - myrtenal significantly decreased MDA, increased the tGSH level and restored catalase (CAT) activity.

In vivo the monoterpenoid exhibits the ability to inactivate free radicals by suppressing colon carcinogenesis in Wistar rats (93) and suppressing tumor progression (94). Our studies on myrtenal confirmed the presence of antioxidant properties in both intact animals and rats with induced dementia models, activating antioxidant protection by stimulating the activity of major endogenous enzymes, suppressing lipid peroxidation levels, and increasing total glutathione levels $(91,92)$.

Myrtenal exhibits an antihyperglycemic effect in rats with a streptozotocin-induced experimental diabetes mellitus model. Under these conditions, myrtenal decreases plasma glucose levels, improves plasma insulin levels, increases regulation of various glucose transporters, and subsequently improves glucose utilization in the liver and skeletal muscles (95). Oral administration of myrtenal for 28 days caused the following effects in animals with an experimental diabetes model: decreased plasma glucose and hemoglobin Alc (HbAlc); increased levels of insulin and hemoglobin; restored body weight; normalized hexokinase, glucose-6-phosphatase, fructose-1,6-bisphosphatase, glucose-6-phosphate dehydrogenase and hepatic enzymes AST, ALT and ALP; elevated glycogen content in the liver and muscles; hepatocyte recovery; improved levels of pancreatic insulin and lipid profile (TC (total cholesterol), TG (triglycerides), phospholipids, LDL (low-density lipoproteins), VLDL (very low-density lipoproteins), atherogenic index) (96). Our experimental data confirm the available evidence of the ability of myrtenal to improve the lipid profile in intact laboratory rats (91). In myrtenal-treated animals a significant decrease in plasma levels of TC, TG and LDL along with increased HDL (high density lipoproteins) was observed.

Myrtenal is relatively little studied in the field of neuroscience. The known ligand of one of the olfactory neurons in mammals (hVN1R1) is myrtenal 
Stela Dragomanova, Lyubka Tancheva, Marieta Georgieva

(EC50 1 $\mu \mathrm{M})$ (97). Its chemical characterization and its physicochemical properties (98) include an assumption of its probable membrane stabilizing properties (99), and its lipophilic nature suggests its CNS effect due to its ability to pass the blood-brain barrier.

Our experimental studies on the CNS effects of myrtenal ((-)-myrtenal, 98\%, purchased from ACRŌS Organics, Lot: A0363097) in laboratory rodents have shown the potentiation of the effects of classical hypnotic medicines. The substance administered at a single dose significantly prolonged the hypnotic-sedative effects of barbiturates (Barbital sodium) and benzodiazepines (diazepam). These effects were likely to exhibit central mechanisms of action and result from the interaction of myrtenal with the GABA receptor. Data from the literature reported similar effects of newly synthesized analogues of myrtenal on the GABA-ergic system (100). Similar results for improved hypnotic effects of barbiturates in mice have been reported for Myrtus communis essential oil and water-alcohol plant extract $(101,102)$. Our data of myrtenal's potentiating activity on classic hypnotic drugs (barbiturates) effects in combination (103) also confirm the results obtained by other researchers (77).

In agreement with the above-mentioned authors, we believe that the mechanism of this response is predominately central. It is not due to metabolic interactions of myrtenal with barbiturates at the level of hepatic metabolism. In other studies of ours (103), myrtenal did not influence the hypnotic effect and metabolism of Hexobarbital sodium (a model substrate of CYP450 monooxygenases).

A probable central mechanism of action of myrtenal is the response to GABA neurotransmission associated with the anxiolytic properties of the substance. The studies of Hailu et al. (2011) found good anxiolytic properties of myrtle essential oil comparable to those of diazepam as a standard (75).

Our studies on mice also found a significant anxiolytic effect of myrtenal (Marble burying test) comparable to that of diazepam as a reference (103). According to some authors, the whole complex of biologically active substances (76), like the hydroxyl derivative myrtenol (essential oil component), have anxiolytic properties (102) with possible mechanism of response to GABA neurotransmission.
The available scientific data as well as our own results give us a reason to suppose that myrtenal is a potential carrier of these pharmacological effects. This is also confirmed by the reported anxiolytic activity of synthesized myrtenal analogues in mice (100). The same authors found that the main mechanism of action is influencing the GABA- as well as the DA-ergic system in rodents.

There is still limited data in the literature on the effects of myrtenal on the major brain neurotransmitters levels. The reported inhibitory effects of myrtenal on acetylcholinesterase activity in vitro (104) have not been confirmed in in vivo experiments, including in our own experiments on mice (105).

Neuromodulatory activity of myrtenal was established after its repeated (14 days) administration in laboratory rats. Myrtenal significantly increased the levels of three major mediators in the brains acetylcholine (ACh), 5-hydroxytriptamine (5-HT) and dopamine (DA) in comparison to controls. These data were confirmed by better performance of myrtenal-treated rodents in memory and learning status than in controls (106). We assume that the observed central effects of myrtenal were probably due to the lipophilic nature of its molecule, which determines a better distribution in the CNS (78).

Despite the reported myrtenal acetylcholinesterase activity inhibiting effects in vitro to warrant the authors suggesting its ability to affect memory in experimental dementia, data on its effects on animal models of neurodegeneration were not found in the literature.

Our studies have found pronounced improvement effects of myrtenal (in single and multiple application) on memory and learning in rodents with experimental (scopolamine-induced) dementia (107) associated with the neuromodulatory action of myrtenal. Compared to controls, elevated levels of major brain neurotransmitters - noradrenaline (NA), DA, ACh and 5-HT, in the brain of mytenaltreated animals were observed.

The preventive effect of myrtenal on the course of the neurodegenerative process was confirmed in our other studies in rats with an experimental model (6-OHDA-induced) of Parkinson's disease (PD). Delayed course of disease, improved motor coordination and improved cognitive function were observed 
compared to untreated rats with PD. These results were accompanied by preserved levels of dopamine in the brains of myrtenal-treated rats in comparison to 6-OHDA control rats (unpublished data).

In addition to the presence of neuromodulatory activity of myrtenal, significant antioxidant effects were detected in ICR mice and Wistar rats with neurodegenerative disease models (AD and PD). Myrtenal caused memory improvement in the behavioral tests and had a positive effect on altered oxidative status induced by scopolamine - decreased MDA and increased tGSH level, as well as restored CAT activity in the animal's brain. Obviously, the established neuroprotective effects of myrtenal are due to its complex mechanisms of action, both neuromodulatory and antioxidant ones $(108,109)$.

\section{CONCLUSION}

Significant improving effects of myrtenal on memory and learning in experimental rodents, as well as its protective effects on neurodegenerative processes are established. Probably they are related to its complex mechanisms of action. At least two mechanisms are involved in the established protecting effects of myrtenal on the neurodegenerative processes - neuromodulatory and antioxidant but they deserve more detailed studies.

\section{Aknowledgements}

The research was supported by Project No 14014 funded by the Science Fund at the Medical University of Varna, Bulgaria.

\section{REFERENCES}

1. Zhang L, Demain AL (Eds.) Natural products: drug discovery and therapeutic medicine. Humana Press Inc.; 2005.

2. Yoo KY, Park SY. Terpenoids as potential anti-Alzheimer's disease therapeutics. Molecules. 2012;17(3):3524-8. doi: 10.3390/molecules17033524.

3. Boskabady MH, Jandaghi P. Relaxant effects of carvacrol on guinea pig tracheal chains and its possible mechanisms. Pharmazie. 2003;58(9):661-3.

4. Nazzaro F, Fratianni F, De Martino L, Coppola R, De Feo V. Effect of essential oils on pathogenic bacteria. Pharmaceuticals (Basel). 2013; 6(12):1451-74.

5. Eccles R. Menthol and Related Cooling Compounds. J Pharm Pharmacol. 1994; 46: 618-30.
6. Brum LFS, Elisabetsky E, Souza D. Effects of linalool on $[3 \mathrm{H}] \mathrm{MK} 801$ and $[3 \mathrm{H}]$ muscimol binding in mouse cortical membranes. Phytother Res. 2001;15(5):422-5.

7. Park TJ, Park YS, Lee TG, Ha H, Kim KT. Inhibition of acetylcholine-mediated effects by borneol. Biochem Pharmacol. 2003;65(1):83-90.

8. Habtemariam S. Antidiabetic Potential of monoterpenes: A case of small molecules punching above their weight. Int J Mol Sci. 2017;19(1). pii: E4. doi: 10.3390/ijms19010004.

9. Subramaniyan SD, Natarajan AK. Citral, a monoterpene protect against high glucose induced oxidative injury in HepG2 cell in vitro-an experimental study. J Clin Diagn Res. 2017; 11(8): BC10-BC15. doi: 10.7860/JCDR/2017/28470.10377.

10. Varghese GK, Bose LV, Habtemariam S. Antidiabetic components of Cassia alata leaves: Identification through a-glucosidase inhibition studies. Pharm Biol. 2013; 51(3):345-9. doi: 10.3109/13880209.2012.729066.

11. Zhang Y, Yaqin D, Xiangqin Z, Qing G, Hui W, Jingying $\mathrm{G}$, et al. Geniposide acutely stimulates insulin secretion in pancreatic $\beta$-cells by regulating GLP-1 receptor/cAMP signaling and ion channels. Mol Cell Endocrinol. 2016;430:89-96. doi: 10.1016/j. mce.2016.04.020.

12. Ramakrishnan $M$, Ramalingam $S$. Antidiabetic effect of d-limonene, a monoterpene in streptozotocin-induced diabetic rats. Biomed Prevent Nutr. 2012; 2(4):269-75. doi: 10.1016/j.bionut.2012.08.008.

13. Luft VC, Schmidt MI, Pankow JS, Couper D, Ballantyne CM, Young JH, et al. Chronic inflammation role in the obesity-diabetes association: a casecohort study. Diabetol Metab Syndr. 2013;5(1):31. doi: 10.1186/1758-5996-5-31.

14. Kong P, Chi R, Zhang L, Wang N, Lu Y. Effects of paeoniflorin on tumor necrosis factor- $\alpha$-induced insulin resistance and changes of adipokines in 3T3-L1 adipocytes. Fitoterapia. 2013;91:44-50. doi: 10.1016/j.fitote.2013.08.010.

15. De Sousa DP. Analgesic-like activity of essential oils constituents. Molecules. 2011;16(3):2233-52. doi: 10.3390/molecules16032233.

16. Samaila D, Toy BJ, Wang RC, Elegbede JA. Monoterpenes enchanced the sensitivity of head and neck cancer cells to radiation treatment in vitro. Anticancer Res. 2004;24(5A):3089-95. 
Stela Dragomanova, Lyubka Tancheva, Marieta Georgieva

17. Fang F, Li H, Qin T, Li M, Ma S. Thymol improves high-fat diet-induced cognitive deficits in mice via ameliorating brain insulin resistance and upregulating NRF2/HO-1 pathway. Metab Brain Dis. 2017;32(2):385-393. doi: 10.1007/s11011-016-9921-z.

18. Deng W, Lu H, Teng J. Carvacrol attenuates diabetes-associated cognitive deficits in rats. J Mol Neurosci. 2013;51(3):813-9. doi: 10.1007/ s12031-013-0069-6.

19. Miyazawa M, Yamafuji C. Inhibition of acetylcholinesterase activity by bicyclic monoterpenoids. J Agric Food Chem. 2005;53(5):1765-8. doi: 10.1021/ jf040019b.

20. Moraghebi F. Introduction of mirtenal as an indicator component in essential oil of Cuminum cyminum Isfahan variety. J Biodivers Environ Sci. 2013; 3(11):112-7.

21. El Ghadraoui L, Essakhi D, Benjelloun M, Errabhi N, El Harchli H, Alaoui MM, et al. Chemical composition of essential oils from Rosmarinus officinalis L. and acridicide activity on Dociostaurus maroccanus Thunberg, 1815 in Morocco. Int J Sci Eng Res. 2015; 6(8):166-72.

22. Pino JA, Rosado A, Fuentes V. Chemical composition of the seed oil of Coriandrum sativum L. from Cuba. J Essent Oil Res. 1996; 8(1):97-8. doi: 10.1080/10412905.1996.9700565.

23. Kizil S, Haşimi N, Tolan V, Kilinç E, Karataş H. Chemical composition, antimicrobial and antioxidant activities of Hyssop (Hyssopus officinalis, L) essential oil. Not Bot Hort Agrobot Cluj-Napoca. 2010; 38(3):99-103. doi: 10.15835/nbha3834788.

24. Smigielski K, Raj A, Krosowiak K, Gruska R. Chemical composition of the essential oil of Lavandula angustifolia cultivated in poland. J Essent Oil Bear Pl. 2009;12(3):338-47. doi: 10.1080/0972060X.2009.10643729.

25. Radulović NS, Randjelović PJ, Stojanović NM, Blagojević PD, Stojanović-Radić ZZ, Ilić IR, et al. Toxic essential oils. Part II: Chemical, toxicological, pharmacological and microbiological profiles of Artemisia annua L. Volatiles. Food Chem Toxicol. 2013;58:37-49. doi: 10.1016/j.fct.2013.04.016.

26. Wong K, Chong T, Chee S. Essential oil of Curcuma mangga Val. and van Zijp rhizomes. J Essent Oil Res. 1999; 11(3):349-51. doi: 10.1080/10412905.1999.9701151.

27. De Falco E, Mancini E, Roscigno G, Mignola E, Taglialatela-Scafati O, Senatore F. Chemical composi- tion and biological activity of essential oils of Origanum vulgare L. subsp. vulgare L. under different growth conditions. Molecules. 2013;18(12):1494860. doi: 10.3390/molecules181214948.

28. Etievant PX, Azar M, Pham-Delegue MH, Masson CJ. Isolation and identification of volatile constituents of sunflowers (Helianthus annuus L.). J Agric Food Chem. 1984;32(3): 503-9. doi: 10.1021/ jf00123a021.

29. Rather MA, Dar BA, Dar MY, Wani BA, Shah WA, Bhat BA, et al. Chemical composition, antioxidant and antibacterial activities of the leaf essential oil of Juglans regia L. and its constituents. Phytomedicine. 2012;19(13):1185-90. doi: 10.1016/j. phymed.2012.07.018.

30. Blake S. Medicinal Plant Constituents, 2004. Available from: www.NaturalHealthWizards.com

31. Salgueiro LR, Vila R, Tomàs $\mathrm{X}$, Cañigueral S, Paiva J, da Cunha AP, et al. Essential oil composition and variability of Thymus lotocephalus and Thymus $\times$ mourae. Biochem Syst Ecol. 2000;28(5):457-70.

32. Gardeli C, Vassiliki P, Athanasios M, Kibouris T, Komaitis M. Essential oil composition of Pistacia lentiscus L. and Myrtus communis L.: Evaluation of antioxidant capacity of methanolic extracts. Food Chem. 2008; 107(3):1120-30. doi: 10.1016/j. foodchem.2007.09.036.

33. Human Metabolome Database (HMDB) [Internet], Available from: http:/www.hmdb.ca/metabolites/ HMDB0035250

34. Hames-Kocabas EE, Demirci B, Uzel A, Demirci F. Volatile composition of Anatolian propolis by headspace-solid-phase microextraction (HSSPME), antimicrobial activity against food contaminants and antioxidant activity. J Med Pl Res. 2013; 7(28):2140-9. doi: 10.5897/JMPR2013.4470.

35. Sayyah M, Peirovi A, Kamalinejad M. Antinociceptive effect of fruit essential oil of Cuminum cyminum L. in rat. Iran Biomed J. 2002b, 6(4):141-5.

36. Al-Snafi AE. The pharmacological activities of Cuminum cyminum - a review. IOSR J Pharm. 2016; 6(6):46-65.

37. Shivakumar SI, Shahapurkar AA, Kalmath KV, Shivakumar B. Antiinflammatory activity of fruits of Cuminum cyminum Linn. Pharm Lett. 2010; 2(1):22-4. 
38. Hajlaoui H, Mighri H, Noumi E, Snoussi M, Trabelsi N, Ksouri R, et al. Chemical composition and biological activities of Tunisian Cuminum cyminum L. essential oil: a high effectiveness against Vibrio spp. strains. Food Chem Toxicol. 2010;48(89):2186-92. doi: 10.1016/j.fct.2010.05.044.

39. Jirovetz L, Buchbauer G, Stoyanova AS, Georgiev EV, Damianova ST. Composition, quality control and antimicrobial activity of the essential oil of cumin (Cuminum cyminum L.) seeds from Bulgaria that had been stored for up to 36 years. Intl J Food Sci Technol. 2005; 40(3):305-10. doi: 10.1111/j.1365-2621.2004.00915.x.

40. Gagandeep DS, Méndiz E, Rao AR, Kale RK. Chemopreventive effects of Cuminum cyminum in chemically induced forestomach and uterine cervix tumors in murine model systems. Nutr Cancer. 2003; 47(2):171-80. doi: 10.1207/ s15327914nc4702_10.

41. Janahmadi M, Niazi F, Danyali S, Kamalinejad M. Effects of the fruit essential oil of Cuminum cyminum Linn. (Apiaceae) on pentylenetetrazol-induced epileptiform activity in F1 neurones of Helix aspersa. J Ethnopharmacol. 2006;104 (1-2):278-82. doi: 10.1016/j.jep.2005.09.019.

42. Koppula S, Choi D K. Cuminum cyminum extract attenuates scopolamine-induced memory loss and stress-induced urinary biochemical changes in rats: a noninvasive biochemical approach. Pharm Biol. 2011; 49(7):702-8. doi: 10.3109/13880209.2010.541923.

43. Shirke SS, Jagtap AG. Effects of methanolic extract of Cuminum cyminum on total serum cholesterol in ovariectomized rats. Indian J Pharmacol. 2009; 41(2):92-3. doi: 10.4103/0253-7613.51353.

44. Zare R, Heshmati F, Fallahzadeh H, Nadjarzadeh A. Effect of cumin powder on body composition and lipid profile in overweight and obese women. Complement Ther Clin Pract. 2014;20(4):297-301. doi: 10.1016/j.ctcp.2014.10.001.

45. Samani KG, Farrokhi E. Effects of cumin extract on oxLDL, paraoxanase 1 activity, FBS, total cholesterol, triglycerides, HDL-C, LDL-C, Apo A1, and Apo B in in the patients with hypercholesterolemia. Int J Health Sci (Qassim). 2014; 8(1):39-43.

46. Oluwatuy M, Kaatz GW, Gibbons S. Antibacterial and resistance modifying activity of Rosmarinus officinalis. Phytochemistry. 2004; 65(24):3249-54. doi: 10.1016/j.phytochem.2004.10.009.
47. Galistco M, Suarez A, Del Pilar MM, Del Pilar UM, Jimenez J, Gil A, et al. Antihepatotoxic activity of Rosmarinus tomentosus in a model of acute hepatic damage induced by thioacetamide. Phytother Res. 2000; 14(7):522-6.

48. Takaki I, Bersani-Amado LE, Vendruscolo A, Sartoretto SM, Diniz SP, Bersani-Amado CA, et al. Anti-inflammatory and antinociceptive effects of Rosmarinus officinalis L. essential oil in experimental animal models. J Med Food. 2008; 11(4):741-6. doi: 10.1089/jmf.2007.0524.

49. González-Trujano ME, Peña EI, Martínez AL, Moreno J, Guevara-Fefer P, Déciga-Campos M, et al. Evaluation of the antinociceptive effect of Rosmarinus officinalis L. using three different experimental models in rodents. J Ethnopharmacol. 2007; 111(3):476-82. doi: 10.1016/j.jep.2006.12.011.

50. Stefanovits-Banyai E, Tulok MH, Hegedus A, Renner C, Varga IS. Antioxidant effect of various rosemary (Rosmarinus officinalis L.) clones. Acta Biol Szeged. 2003; 47(1-4):111-3.

51. Minaiyan M, Ghannadi AR, Afsharipour M, Mahzouni P. Effects of extract and essential oil of Rosmarinus officinalis L. on TNBS-induced colitis in rats. Res Pharm Sci. 2011; 6(1):13-21.

52. Dias PC, Foglio MA, Possenti A, Carvalho JE. Antiulcerogenic activity of crude hydroalcoholic extract of Rosmarinus officinalis L. J Ethnopharmacol. 2000; 69(1):57-62.

53. Cheung S, Tai J. Anti-proliferative and antioxidant properties of Rosmarinus officinalis. Oncol Rep. 2007; 17(6):1525-31.

54. Raskovic A, Milanovic I, Pavlovic N, Milijasevic B, Ubavic M, Mikov M. Analgesic effects of rosemary essential oil and its interactions with codeine and paracetamol in mice. Eur Rev Med Pharmacol Sci. 2015; 19(1):165-72.

55. Wu Y, Huang J, Zuo A, Yao L. Research on the effects of Rosemary (Rosmarinus officinalis L.) on the blood lipids and anti-lipid peroxidation in rats. J Essent Oil Res. 2011; 23(4):26-34. doi: 10.1080/104 12905.2011.9700465.

56. Zheng T, Moss-Pierce T, Ford P, Jiang TA. Rosemary (Rosmarinus officinalis L.) Extract regulates glucose and lipid metabolism by activating AMPK and PPAR pathways in HepG2 cells. J Agric Food Chem. 2013; 61(11):2803-10. doi: 10.1021/jf400298c.

57. Umezu T. Evaluation of central nervous system acting effects of plant-derived essential oils using am- 
Stela Dragomanova, Lyubka Tancheva, Marieta Georgieva

bulatory activity in mice. Pharmacol Pharm. 2013; 4:160-70. doi:10.4236/pp.2013.42023.

58. Machado DG, Cunha MP, Neis VB, Balen GO, Colla A, Bettio L, et al. Antidepressant-like effects of fractions, essential oil, carnosol and betulinic acid isolated from Rosmarinus officinalis $\mathrm{L}$. Food Chem. 2013; 136(2):999-1005. doi: 10.1016/j. foodchem.2012.09.028.

59. Zanella CA, Treichel H, Cansian RL, Roman SS. The effects of acute administration of the hydroalcoholic extract of rosemary (Rosmarinus officinalis L.) (Lamiaceae) in animal models of memory. Braz J Pharm Sci. 2012; 48(3). doi: 10.1590/ S1984-82502012000300005.

60. Moss M, Cook J, Wesnes K, Duckett P. Aromas of rosemary and lavender essential oils differentially affect cognition and mood in healthy adults. Int J Neurosci. 2003; 113(1):15-38. doi: $10.1080 / 00207450390161903$

61. Habtemariam $S$. The therapeutic potential of rosemary (Rosmarinus officinalis) diterpenes for Alzheimer's disease. Evid Based Complement Alternat Med. 2016;2016:2680409. doi: $10.1155 / 2016 / 2680409$.

62. Park SE, Kim S, Sapkota K, Kim SJ. Neuroprotective effect of Rosmarinus officinalis extract on human dopaminergic cell line, SH-SY5Y. Cell Mol Neurobiol. 2010;30(5):759-67. doi: 10.1007/ s10571-010-9502-3.

63. El Omri A, Han J, Hashizume R, Ben Abdrabbah $\mathrm{M}$, Isoda H. Anti-neuronal stress effect of Tunisian Rosmarinus officinalis extract. J Arid Land Stud. 2009; 19(1):117-20.

64. Cavanagh HM, Wilkinson JM. Biological activities of lavender essential oil. Phytother Res. 2002;16(4):301-8. doi: 10.1002/ptr.1103.

65. Hritcu L, Cioanca O, Hancianu M. Effects of lavender oil inhalation on improving scopolamineinduced spatial memory impairment in laboratory rats. Phytomedicine. 2012; 19(6):529-34. doi: 10.1016/j.phymed.2012.02.002.

66. Rahmati B, Kiasalari Z, Roghani M, Khalili M, Ansari F, Antidepressant and anxiolytic activity of Lavandula officinalis aerial parts hydroalcoholic extract in scopolamine-treated rats, Pharm Biol. 2017;55(1):958-965. doi: 10.1080/13880209.2017.1285320.

67. Gil-Yong L, Lee C, Park G H, Jang J. Amelioration of Scopolamine-Induced Learning and
Memory Impairment by a-Pinene in C57BL/6

Mice. Evid Based Complement Alternat Med. 2017;2017:4926815. doi: 10.1155/2017/4926815.

68. Stefanello MÉ, Pascoal AC, Salvador MJ. Essential oils from neotropical Myrtaceae: chemical diversity and biological properties. Chem Biodivers. 2011;8(1):73-94. doi: 10.1002/cbdv.201000098.

69. Ghazal A, Dashti S, Hosseinzadeh H. Review of pharmacological effects of Myrtus communis L. and its active constituents. Phytother Res. 2014;28(8):1125-36. doi: 10.1002/ptr.5122.

70. Tumen I, Senol FS, Orhan IE. Inhibitory potential of the leaves and berries of Myrtus communis L. (myrtle) against enzymes linked to neurodegenerative diseases and their antioxidant actions. Int J Food Sci Nutr. 2012; 63(4):387-92. doi: 10.3109/09637486.2011.629178.

71. Begum S, Ali M, Gul H, Ahmad W, Alam S, Khan $M$, et al. In vitro enzyme inhibition activities of Myrtus communis L. Afr J Pharm Pharmacol. 2012; 6(14):1083-7. doi: 10.5897/AJPP10.134.

72. Aleksic V, Knezevic P. Antimicrobial and antioxidative activity of extracts and essential oils of Myrtus communis L. Microbiol Res. 2014;169(4):24054. doi: 10.1016/j.micres.2013.10.003.

73. Dairi S, Madani K, Aoun M, Him J L, Bron P, Lauret C, et al., Antioxidative properties and ability of phenolic compounds of Myrtus communis leaves to counteract in vitro LDL and phospholipid aqueous dispersion oxidation. J Food Sci. 2014 Jul;79(7):C1260-70. doi: 10.1111/1750-3841.12517.

74. Hennia A, Miguel MG, Nemmiche S. Antioxidant Activity of Myrtus communis L. and Myrtus nivellei Batt. \& Trab. Extracts: A Brief Review. Medicines (Basel). 2018;5(3):89. doi:10.3390/ medicines 5030089 .

75. Hailu E, Engidawork E, Asres K. Essential oil of Myrtus communis L. produces a non-sedating anxiolytic effect in mice model of anxiety. Ethiopian Pharm J. 2011; 29(1):1-12. doi: 10.4314/epj.v29i1.1.

76. Hajiaghaee R, Faizi M, Shahmohammadi Z, Abdollahnejad F, Naghdibadi H, Najafi F, et al. Hydroalcoholic extract of Myrtus communis can alter anxiety and sleep parameters: a behavioural and EEG sleep pattern study in mice and rats. Pharm Biol. 2016, 54(10):2141-8. doi: 10.3109/13880209.2016.1148175.

77. Birhanie M W, Walle B, Rebba K. Hypnotic effect of the essential oil from the leaves of Myrtus com- 
munis on mice. Nat Sci Sleep. 2016;8:267-75. doi: 10.2147/NSS.S101493.

78. Human Metabolome Database [Internet], Available from: http://www.hmdb.ca/metabolites/ HMDB0035250

79. Ishida T, Toyota M, Asakawa Y. Terpenoid biotransformation in mammals. Metabolism of (+)-citronellal, (+-)-7-hydroxycitronellal, citral, (-)-perillaldehyde, (-)-myrtenal, cuminaldehyde, thujone, and (+-)-carvone in rabbits. Xenobiotica, 1989, 19(8):843-55.

80. Ishida T. Biotransformation of terpenoids by mammals, microorganisms, and plant-cultured cells, Chem Biodiver. 2005; 2(5):569-90. doi: 10.1002/ cbdv.200590038.

81. 2-Formyl-6,6-dimethylbicyclo[3.1.1]hept-2ene. Food Chem Toxicol. 1988; 26(4):329. doi: 10.1016/0278-6915(88)90165-2.

82. Hardie J, Isaacs R, Pickett JA, Wadhams LJ, Woodcock CM. Methyl salicylate and (-)-(1R,5S)-myrtenal are plant-derived repellents for black bean aphid,Aphis fabae Scop. (Homoptera: Aphididae). J Chem Ecol. 1994 Nov;20(11):2847-55. doi: 10.1007/ BF02098393.

83. Negoi A, Parvulescu VI, Tudorache M. Peroxidasebased biocatalysis in a two-phase system for allylic oxidation of $\alpha$-pinene. Catal. Today. 2018; 306:199206. doi: 10.1016/j.cattod.2017.02.052.

84. Vegezzi Davide, United States Patent 1980 [Internet], Available from: http://www.google.fr/patents/ US4190675?hl=fr\&dq=myrt\%C3\%A9nal\#v=onepa ge\&q\&f=false

85. Santos MRV, Moreira FV, Fraga BP, de Souza DP, Bonjardim LR, Quintans-Junior LJ. Cardiovascular effects of monoterpenes: a review. Rev Bras Farmacogn. 2011; 21(4). doi: 10.1590/ S0102-695X2011005000119.

86. Saito $K$, Okabe $T$, Inamori $Y$, Tsujibo H, Miyake Y, Hiraoka K, et al. The biological properties of monoterpenes: Hypotensive effects on rats and antifungal activities on plant pathogenic fungi of monoterpenes. Mokuzai Gakkaishi. 1996; 42:677-80.

87. Hari Babu L, Perumal S, Balasubramanian MP. Myrtenal attenuates diethylnitrosamine-induced hepatocellular carcinoma in rats by stabilizing intrinsic antioxidants and modulating apoptotic and anti-apoptotic cascades. Cell Oncol (Dordr). 2012 Aug;35(4):269-83. doi: 10.1007/s13402-012-0086-4.
88. Hari Babu L, Perumal S, Balasubramanian MP. Myrtenal, a natural monoterpene, down-regulates TNF- $\alpha$ expression and suppresses carcinogen-induced hepatocellular carcinoma in rats. Mol Cell Biochem. 2012 Oct;369(1-2):183-93. doi: 10.1007/ s11010-012-1381-0.

89. Hari Babu L, Natarajan N, Thamaraiselvan R, Srinivasan P, Periyasamy BM. Myrtenal ameliorates diethylnitrosamine-induced hepatocarcinogenesis through the activation of tumor suppressor protein p53 and regulation of lysosomal and mitochondrial enzymes. Fundam Clin Pharmacol. 2013 Aug;27(4):443-54. doi: 10.1111/j.1472-8206.2012.01039.x.

90. Venkatachalam S, Boobathi L, Balasubramanian MP. Salubrious therapeutic efficacy of myrtenal on colon carcinoma induced by 1,2-dimethylhydrazine studied in experimental albino rats. Res J Pharmacol Pharmacodyn. 2014; 6(3):146-52.

91. Dragomanova S, Tancheva L, Klisurov R, Kalfin R. Myrtenal changes brain oxidative status and the lipid profile in experimental rats. ICBA 2018. Available from: https:/www.bio-antioxidants2018.com/

92. Dragomanova $S$, Tancheva L, Alexandrova A, Tzvetanova E, Lazarova M, Pavlova A, et. al. Effects of myrtenal on brain oxidative status in rats with experimental dementia. ICBA 2018. Available from: https:/www.bio-antioxidants2018.com/

93. Boobathi L, Venkatachalam S, N Natarajan, Rengarajan T, Madankumar A, Balasubramanian MP. Anti-oxidative effect of myrtenal in prevention and treatment of colon cancer induced by 1,2-dimethyl hydrazine $(\mathrm{DMH})$ in experimental animals. Biomol Ther (Seoul). 2015;23(5):471-8. doi: 10.4062/ biomolther.2015.039.

94. Booupathy LK, Venkatachalam S, Natarajan N, Thamaraiselvan R, Arumugam M, Maruthaiveeran Periyasamy B. Chemopreventive effect of myrtenal on bacterial enzyme activity and the development of 1,2-dimethyl hydrazine-induced aberrant crypt foci in Wistar rats. J Food Drug Anal. 2016;24(1):206-213. doi: 10.1016/j.jfda.2015.07.003.

95. Rathinam A, Pari L. Myrtenal ameliorates hyperglycemia by enhancing GLUT2 through Akt in the skeletal muscle and liver of diabetic rats. Chem Biol Interact. 2016; 256:161-6. doi: 10.1016/j. cbi.2016.07.009.

96. Rathinam A, Pari L. Myrtenal alleviates hyperglycaemia, hyperlipidaemia and improves pancreatic insulin level in STZ-induced diabet- 
Stela Dragomanova, Lyubka Tancheva, Marieta Georgieva

ic rats. Pharm Biol. 2016;54(11):2521-7. doi: 10.3109/13880209.2016.1168852.

97. Corin K, Baaske P, Geissler S, Wienken CJ, Duhr $S$, Braun D, et al. Structure and function analyses of the purified GPCR human vomeronasal type 1 receptor 1. Sci Rep. 2011;1:172. doi: 10.1038/ srep00172.

98. National Center for Biotechnology Information. PubChem Compound Database; $\mathrm{CID}=61130$, https://pubchem.ncbi.nlm.nih.gov/compound/61130 (accessed Jan. 23, 2019). Available from: https://pubchem.ncbi.nlm.nih.gov/ compound/Myrtenal

99. Avgustinovich DF, Fomina MK, Suslov EV, Tolstikova TG, Volcho KP, Salakhutdinov NF. Effect of 2-aminoadamantane derivatives on behavior of mice in a modified light/dark test. Bull Exp Biol Med. 2014;158(2):213-8. doi: 10.1007/ s10517-014-2725-4.

100. Miraj S. A review study of therapeutic effect of Myrtus communis. Der Pharm Lett. 2016;8(9):281-5.

101. Walle M, Walle B, Zerihun L, Makonnen E. Sedative-hypnotic like effect of the essential oil from the leaves of Myrtus Communis on mice. Am J Biomed Life Sci. 2014, 2(4):70-7. doi: 10.11648/j. ajbls.20140204.12.

102. Moreira MR, Salvadori MG, de Almeida AA, de Sousa DP, Jordán J, Satyal P, et al. Anxiolytic-like effects and mechanism of (-)-myrtenol: a monoterpene alcohol. Neurosci Lett. 2014;579:119-24. doi: 10.1016/j.neulet.2014.07.007.

103. Stoeva S, Georgieva M, Dragomanova S, Tancheva L. Study of the sedative-hypnotic and anxiolytic properties of myrtenal. Scr Sci Pharm. 2017; 4(Suppl 2):12.

104. Kaufmann D, Dogra AK, Wink M. Myrtenal inhibits acetylcholinesterase, a known Alzheimer target. J Pharm Pharmacol. 2011; 63(10):1368-71. doi: 10.1111/j.2042-7158.2011.01344.x.
105. Dragomanova S, Tancheva L, Georgieva M, Georgieva A, Dishovsky C, Stoeva S, et al. Effect of monoterpene myrtenal on experimental dementia in mice. 31st International Conference of Alzheimer's Disease, 24-26 April 2016, Budapest, Hungary. Available from: https://www.alz.co.uk/ ADI-conference-2016

106. Dragomanova S, Klisurov R, Georgieva M, Lazarova M, Dishovsky C, Kalfin R, et al. Effect of myrtenal on social behavior and memory of rats. 10th Congress of Toxicology in Developing Countries (CTDC10), 18-21 April, 2018, Belgrade, Serbia. Available from: http://www.ctdc10.rs/

107. Dragomanova S, Tancheva L, Georgieva M, Klisurov R, Lazarova M, Alexandrova A, et al. Study on the mechanism of neuroprotective effect of myrtenal on rats with experimental dementia. AAIC, 2017. Available from: www.alz.org/varna

108. Dragomanova S, Tancheva L, Georgieva M, Georgieva A, Stoeva S, Kalfin R. Antioxidant mechanism in the preventive effect of myrtenal on Alzheimer's disease progression on experimental mouse model. European College of Neuropsychopharmacology, Amsterdam, The Nederlands, 2015, Abstract book of ECNP 2015. 2015; 25(Suppl. 2):S578-9. doi: 10.1016/S0924-977X(15)30812-9. Available from: http://www.europeanneuropsychopharmacology.com/action/showMultipleAbstracts? prg140729=1625c197-54a1-485b-b5ef-777aeafd6bac

109. Klisurov R, Dragomanova S, Tancheva L, Kalfin R. Study on the neuroprotective mechanisms of myrtenal on experimental rats. 2ND INTERNATIONAL BIOMEDICAL CONGRESS 2017, Sofia, Bulgaria. Abstract book. p. 39. Available from: https://ibc-sofia.org/ 